\title{
Regional variation in fire weather controls the reported occurrence of Scottish wildfires
}

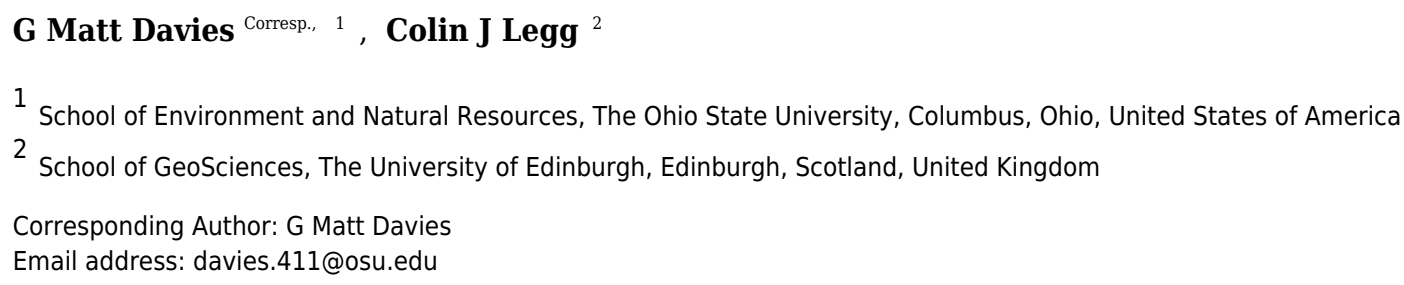

Fire is widely-used as a traditional habitat management tool in Scotland but wildfires pose a significant and growing threat. The financial costs of fighting wildfires are significant and severe wildfires can have substantial environmental impacts. Due to the intermittent occurrence of severe fire seasons, Scotland, and the UK as a whole, remain somewhat unprepared. Scotland currently lacks any form of Fire Danger Rating system that could inform managers and the Fire and Rescue Services (FRS) of periods when there is a risk of increased of fire activity. We aimed evaluate the potential to use outputs from the Canadian Fire Weather Index system (FWI system) to forecast periods of increased fire risk and the potential for ignitions to turn into large wildfires. We collated four and a half years of wildfire data from the Scottish FRS and examined patterns in wildfire occurrence within different regions, seasons, between urban and rural locations and according to FWI system outputs. We used a variety of techniques, including Mahalanobis distances, percentile analysis and Thiel-Sen regression, to scope the best performing FWI system codes and indices. Logistic regression showed significant differences in fire activity between regions, seasons and between urban and rural locations. The Fine Fuel Moisture Code and the Initial Spread Index did a tolerable job of modelling the probability of fire occurrence but further research on fuel moisture dynamics may provide substantial improvements. Overall our results suggest it would be prudent to ready resources and avoid managed burning when FFMC $>75$ and/or ISI $>2$. 
1

2

\title{
REGIONAL VARIATION IN FIRE WEATHER CONTROLS THE REPORTED OCCURRENCE OF SCOTTISH WILDFIRES
}

\author{
G. Matt Davies ${ }^{1 *} \&$ Colin J. Legg ${ }^{2}$
}

${ }^{1}$ School of Environment and Natural Resources, The Ohio State University, Kottman Hall, 2021 Coffey Road, Ohio, 43210, United States of America

${ }^{2}$ School of GeoSciences, The University of Edinburgh, Crew Building, King's Buildings, West Mains Road, Edinburgh, EH9 3JN, Scotland, United Kingdom

${ }^{*}$ Corresponding author: G. Matt Davies - Phone: 001-614-292-3567; Email: davies.411@osu.edu

\section{ABSTRACT}

Fire is widely-used as a traditional habitat management tool in Scotland but wildfires pose a significant and growing threat. The financial costs of fighting wildfires are significant and severe wildfires can have substantial environmental impacts. Due to the intermittent occurrence of severe fire seasons, Scotland, and the UK as a whole, remains somewhat unprepared. Scotland currently lacks any form of Fire Danger Rating system that could inform land-managers and the Fire and Rescue Services (FRS) of periods when there is a risk of increased of wildfire activity. 
21 We aimed to evaluate the potential use of outputs from the Canadian Fire Weather Index system

22 (FWI system) to forecast periods of increased fire risk, and the potential for ignitions to turn into

23 large wildfires. We collated four and a half years of wildfire data from the Scottish FRS and

24 examined patterns in wildfire occurrence within different regions, seasons, between urban and

25 rural locations and according to FWI system outputs. We compared a variety of commonly-used

26 techniques, including Mahalanobis distances, percentile analysis and Thiel-Sen regression, to

27 scope the best performing FWI system codes and indices with consistent results. Subsequent

28 logistic regression showed significant differences in fire activity between regions, seasons and

29 between urban and rural locations. The Fine Fuel Moisture Code and the Initial Spread Index

30 showed tolerable ability to model the probability of fire occurrence but further research on fuel

31 moisture dynamics may provide substantial improvements. Overall our results suggest it would

32 be prudent to ready resources and avoid managed burning when FFMC $>75$ and/or ISI $>2$. 


\section{INTRODUCTION}

Globally, fire is one of the preeminent disturbances controlling the structure of ecosystems and the services they deliver (Archibald et al. 2013). Although wildfires are a natural component of many ecosystems, in others they are associated with human land-uses and management of fire regimes has played a critical role in the development of many valuable ecosystems (e.g. Webb 1998). Wildfires can, however, also pose significant threats the ecological, economic and cultural resources and there is growing concern over how wildfire activity may be altered by a changing climate (e.g. Scholze et al. 2006, Doerr et al. 2016). Many countries invest significant resources in fire management and wildfire fighting with attention increasingly on adapting fire regimes rather than outright fire suppression (e.g. Peterson et al. 2011, Stephens et al. 2013). A critical part of any response system to manage wildfire is the need to be able to plan for periods of significant wildfire activity and safely complete managed burning activities. Substantial research has therefore been focused on the assessment of global (e.g. Scholze et al. 2006), national (e.g. Tanskanen \& Venäläinen 2008, de Jong et al. 2015) and regional (e.g. Dimitrakopoulos et al. 2010, Beccari et al. 2015) assessments of climatic drivers of wildfire activity. Modeling wildfire activity remains challenging both due to the quality of historical fire data available from documentary records and satellite data (Murphy et al. 2000, Krawchuk \& Mortiz 2014), and the statistical challenges involved (e.g. Andrews et al. 2003, Eastaugh et al. 2012, de Jong et al. 2015). In addition our understanding of wildfire regimes remains incomplete in many regions even though the environmental imperative for improving knowledge is significant. In northern ecosystems, for example, there is very significant concern about potential feedbacks between climate change, wildfire activity and severity, and ecosystem carbon dynamics (Dorrepaal et al. 2006, Turetsky et al. 2015). 
57 Fire is an integral part of the ecology of the British uplands. Traditional managed burning is

58

59

60

61

62

63

64

used extensively for habitat management for red grouse (Lagopus lagopus scoticus Latham 1787) on heather (Calluna vulgaris (L.) Hull) dominated moorlands and blanket bogs, and to rejuvenate moorland and grassland (principally where dominated by purple moor grass, Molinia caerulea (L.) Moench in the latter case) for cattle, sheep and deer grazing (Thompson et al., 1995). In forests prescribed fire has also been used as a ground preparation tool prior to planting (Aldhous \& Scott, 1993) and to facilitate the restoration in native woodlands (Hancock et al. 2009). Whilst there continues to be substantial debate about the environmental costs and benefits of managed burning, particularly in relation to the effect of fire on carbon dynamics (e.g. Glaves, et al. 2013; Davies et al. 2016a), land-managers, conservationists and government agencies are increasingly aware of the potential for severe wildfires to cause substantial environmental damage (e.g. Maltby et al., 1992, Davies et al., 2013). Wildfires are a common occurrence in grass and shrub dominated moorland vegetation and in gorse (Ulex europaeus L.) stands and close to urban areas (Legg et al., 2007). Wildfires within forests in Scotland are much less common, though they do occur during exceptional weather conditions and in young plantations of conifers, especially where these are adjacent to heather or grass-dominated vegetation, or where heather has re-invaded older stands after thinning (Aldhous \& Scott, 1993). Although there are reports in the UK of naturally-occurring wildfires associated with lightning ignitions (e.g. Allison, 1954), the British climate means that in most years a very high proportion of, if not all, wildland fires are of anthropogenic origin initiating as accidental fires, as escaped management burns, or from arson.

Wildfire activity is widely-expected to increase across the British uplands and increased wildfire activity and severity is recognised as one of the more significant threats to UK 
80 biodiversity (Sutherland et al., 2008). These projected trends are driven by: fuel accumulation

81 associated with changes in sheep stocking rates (Acs et al., 2010); pressure to reduce the extent

82 of, or even ban, managed burning (Backshall, Manley \& Rebance, 2001, Davies et al., 2016a);

83 climate change predictions suggesting summers will become warmer and drier with more

84 frequent droughts (Jenkins et al., 2009); and increased ignition frequencies associated with

85 widening public land access (Land Reform (Scotland) Act 2003) and in England and Wales

86 (Countryside \& Rights of Way Act 2000, the so-called CROW Act). The economic cost of

87 wildfires in the UK cannot be easily estimated but they are likely to be substantial. The economic

88 costs include the destruction of property (forestry, fencing, etc.), lost income from reduced land

89

90

91

92

93

94 productivity, and the costs of suppression for land-managers and local agencies (Farmer, 2003, Joint Arson Group, 2007). The environmental costs of wildfire can also be considerable, particularly where peat is ignited resulting in destruction of the seedbank, a higher risk of erosion and a complete change in ecosystem function (e.g. Maltby et al.1990, Davies et al. 2013).

A coherent approach to developing wildfire management policy is slowly emerging in the UK but a robust Fire Danger Rating System is still needed (Gazzard et al. 2016). The difficulties and costs associated with development of such a system are considerable. For example, in New Zealand, fire behaviour and fuel moisture in similar shrub-dominated fuel types and temperate climates have previously proven to be challenging to model (Alexander, 2008). Globally a number of countries have investigated or adopted the Canadian Fire Weather Index System (FWI System; Table 1) to provide forecasts of wildfire danger (e.g. DaCamara et al. 2014, Simpson et al. 2014). A limited system currently exists in the form of the Met Office Fire Severity Index (MOFSI; Kitchen et al., 2006) developed for England and Wales in response to the CROW Act. MOFSI is based on the FWI system which recent research suggests has promise for detecting 
103 variation in fire risk across the UK despite important regional variation in temporal patterns in

104 FWI system codes/indices (de Jong et al. 2016). MOFSI's single five-point index is not sufficient

105 to capture variation in weather and fuel conditions that are of interest to those who work with

106 vegetation fires in the UK or who are responsible for responding to wildfire events. At present

107 The Met Office do not make the underlying codes and indices of the FWI system available

108 though the full suite of outputs are available from the European Forest Fire Information System

109 which provides up to six-day forecasts on a 10-km grid for the whole of Europe. Previous

110 research in the UK has suggested that the Duff Moisture Code and Drought Code of the FWI

111 system (relating respectively to the moisture content of partially decomposed and deep organic

112 matter) show promise in forecasting fire severity (Davies et al., 2013, Davies et al., 2016b), and

113 that the Fine Fuel Moisture Code (FFMC) may be a tolerable predictor of the wildfire activity

114 (Legg et al., 2007).

115 This paper's aims is to develop guidelines for forecasting potential wildfire activity by using

116 wildfire occurrence data from four regions of the Scottish Fire and Rescue Service (see

117 Appendix 1) to meet three objectives: i) compare the results of differing methodologies that can

118 be used to assess the performance of fire risk indices; ii) describe broad temporal and spatial

119 patterns of wildfire occurrence in Scotland; and iii) model the relationship between wildfire

120 occurrence, event magnitude and fuel moisture codes and fire weather indices provided by the

121 FWI system. We acknowledge that, as Finney (2005) pointed out, wildfire occurrence data do

122 not allow us to model wildfire probability per se. The serious constraints on our data are

123 discussed below. Nevertheless, a better understanding of the relationship between wildfire

124 occurrence and fire weather conditions has the potential to contribute significantly to fire

125 management where there is currently no information at all. 


\section{MATERIALS \& METHODS}

127

\section{Wildfire incidents}

128 Securing accurate information on wildfire activity has, until very recently, not been a simple

129 task. There is no central repository for such information and different regional Fire and Rescue

130 Services (FRS), though nominally all using the "Incident Reporting System" (DCLG, 2012),

131 held their own information and recorded wildfire data that varied considerably in scope and

132 quality. Furthermore, we know from experience that the FRS by no means attends all wildfires

133 with call-out rates likely to vary significantly across the U.K. For instance in rural, upland areas,

134 where traditional managed burning is still prevalent, gamekeepers and land-managers have

135 historically been reluctant to involve the FRS. In such locations reporting of fires is likely to be

136 incomplete for social reasons and due to sheer remoteness. The data available is therefore

137 probably biased towards smaller burns in accessible and/or more urban areas.

138 We received data on 4,343 wildfire incidents from four former regional Fire Authorities across

139 Scotland (Appendix 1, Figure S1). The data covered the period between 2003 and spring 2007

140 though this varied somewhat by region. For the purposes of analysis the fire records were

141 restricted to those within the period between $1^{\text {st }}$ January 2003 and $15^{\text {th }}$ March 2007 . This

142 provides a minimum 30-day lead-in time for calculation of the FWI system codes/indices for

143 which Met Office data were available (see below). The data from the Lothian \& Borders FRS

144 only ran to August 2006, so the overall data set does not have equal spatial coverage of all

145 years/months and the data for Lothian \& Borders is slightly biased towards the spring and 146 summer. 
147 The content of the data provided was very variable ranging from simple records of date and

148 location to more detailed descriptions that included the personnel and equipment used to fight the

149 fire, the burn area and the vegetation type burnt. Interpretation was made more complex by the

150 fact that the four regions used different criteria for describing the fire and resources used.

151 Although most records came with a descriptor of fuel type, the terminology used was imprecise

152 and inconsistent. Thus "moorland fire" and "heath fire" might include vegetation dominated by

153 heather or grass whilst the term 'grass fire' appeared, in some cases, to be used for wildfires in

154 general, including those in heather and gorse. The records also included fuel types referred to as

155 crop and stubble, woodland, forest, bushes, hedges and gorse. Fires included in a category

156 described as other (including bonfires, vehicles, rubbish or unspecified) were excluded for this

157 analysis. We classified each of the fire locations as being urban or rural, where urban records

158 were defined in our database as those occurring within the periphery of the 100 largest towns and

159 cities in Scotland.

160 Information about the magnitude of fires varied from estimates of the area burned to precise

161 measures of the number of man-hours involved. The magnitude of each incident was scored by

162 assigning a score from 0-5 for duration of the incident (between report time and all F\&RS

163 returning to base), the area burnt, the number of appliances in attendance, the number of

164 "resources" used (assumed to be the number of F\&RS people in attendance), "Number in

165 attendance" (it is not clear if this included non-F\&RS personnel) and number of person hours.

166 The scoring system is described in detail in Legg et al. (2007). The different data sets presented

167 very different types of information and it was not possible to analyse these data directly so the

168 maximum of the above values for any one fire was recorded as the overall measure of that

169 event's magnitude. There were rather few fires with a maximum score of 4 so the final index was 
170 created by merging classes 3 and 4 . This formed an arbitrary 5-point scale where 0 indicates that

171 the incident was small by all counts and $\geq 4$ indicates that the incident was in about the top $10 \%$

172 with respect to one or more of duration, area burned or resources deployed. For subsequent

173 analysis we defined fires with a final score of 4 or 5 as "large fires". We acknowledge that this

174 measure is rather crude but until such time as we have available data for a number of years with

175 consistent recording of fire area, fire severity or fire behaviour it is the best currently available.

176 From mapping the locations of the fires it was apparent that, for a substantial number of the

177 records, the location recorded was where the fire was reported from or where fire-fighting

178 resources were marshalled rather than the core or ignition point of the fire itself. We assume this

179 will not have substantial impact on the accuracy of FWI system values assigned as these are

180 calculated at a broad spatial scale (see below). Combined with the lack of accurate information

181 on vegetation burnt it did, however, mean that we were unable to account for variation in fuel

182 type at this stage. Previous authors have noted similar issues regarding historical fire records in 183 other studies (e.g. Murphy et al. 2000, Krawchuk \& Moritz 2014) but given the quantity of data

184 available and the broad spatial scale at which analysis was completed we were confident of being 185 able to detect important fire weather signals from our admittedly noisy data.

\section{Fire Weather Data}

187 Indices and codes of the FWI system were calculated for the dates and locations of all recorded 188 wildfires. Data used for the calculation of the FWI system were provided by the Met Office from 189 their Numerical Weather Prediction now-casting model in NIMROD data format. Data 190 represented the predicted weather variables at the centre of a $5 \mathrm{~km}$ grid-square on the Ordnance 191 Survey National Grid. A detailed description of all the weather data received and analysed is 192 provided in Legg et al. (2007). We chose to use this data for three reasons: i) data from widely- 
193 distributed observational stations was unlikely to be representative of conditions at the fire

194 ground due to complex terrain; ii) it represented the form and quality of data that would be used

195 in any implemented version of a fire danger rating system; and iii) this data is also used to drive

196 the Met Office Fire Severity Index and its spatial resolution is favourable compared to previous,

197 similar studies in Europe (e.g. Padilla \& Vega-Garcia, 2011).

198 The six standard components of the FWI system (FFMC, DMC, DC, BUI, ISI and FWI) were

199 calculated using the equations given in Van Wagner \& Picket (1985). Met Office data were

200 available from $1^{\text {st }}$ December 2002 so the minimum lead-in time for fires in January 2003 was 31

201 days.

\section{Data Analysis}

203 The distribution of wildfires is non-random in both time and space. In particular, fuel hazard in

204 spring, with abundant dead herbaceous and aerial shrub fuels, is quite different from that in

205 summer where most above-ground fuel is live. Additionally grass fuels are more abundant in the

206 north-west of Scotland. Fires are more frequent in spring and summer, but can occur at any time

207 of year. To test the discriminating power of the fire weather indices we therefore required a set of

208 weather data that represent "typical" weather conditions, independent of the occurrence of fire,

209 but which has the same spatial and temporal distribution as the weather records for locations and

210 days on which fires were reported. Thus for each fire, the FWI system indices were calculated

211 for a "control day" in the same grid square on the same calendar day but in the year prior to the

212 fire. For fires in 2003 the calculations were for the same day in 2006. This provides a baseline

213 distribution of values for each index against which the characteristics of fire days can be

214 compared. We acknowledge that our control days are pseudo-absences and it is impossible to

215 rule out the possibility that unreported fires occurred in the control dates and locations. We also 
216 acknowledge that wildfires in our region are often ignition limited as rapidly-spreading, intense

217 fire behaviour has been shown to occur even at very low ISI and FWI values in our shrubland

218 fuel types (Davies et al., 2006). We worked under the hypothesis that the FWI system would still

219 capture useful variation in fire weather conditions that might reflect the potential for wildfires

220 due to escaped burns and increased propensity for accidental ignitions during particularly dry

221 conditions.

222 Our analysis followed a two stage process where we first screened the outputs of the FWI

223 system to identify those codes or indices that appeared to discriminate best between fire and

224 control days. Initially, we examined conditional probability curves for each output, calculated

225 using the "cdplot" function in R 3.1.2 (R Core Development Team, 2014), and histograms of the

226 distributions of fire day and control day output values. Further scoping followed the approaches

227 described by Andrews et al. (2003) and Eastaugh et al. (2012). We used the Mahalanobis

228 distance (Equation 1; Viegas et al., 1999) to examine the ability of the FWI system outputs to

229 discriminate between fire days and control days and between large fire days and control days.

230 Mahalanobis distances were calculated both for the whole dataset and separately for each season

231 and region as:

232

$$
\mathrm{Md}=\left[\left(\mathrm{X}_{\mathrm{f}}-\mathrm{X}_{\mathrm{c}}\right) / \sigma\right]^{2}
$$

$233 \mathrm{X}_{\mathrm{f}}=$ mean fire-day index/code value, $\mathrm{X}_{\mathrm{c}}=$ mean control day index/code value; $\sigma=$ standard

234 deviation of index/control value on combined fire and control days. All calculations were

235 completed in $\mathrm{R}$.

236 Our percentile analysis develops that described by Andrews et al. (2003) by taking advantage

237 of the paired nature of our large dataset (i.e. fire and control day observations with the same 
238 spatial and temporal distribution). Andrews et al. (2003) compared fire days with all days in their

239 dataset (i.e. fire days and non-fire days combined). We examined this approach but also

240 examined two other related approaches:

1. We ranked the indices for control and fire days combined and examined the $90^{\text {th }}, 50^{\text {th }}$ and $25^{\text {th }}$ percentiles of each index/code on fire days with those for control days

2. We fitted a cubic spline curve (function "smooth.spline" in R) to model the control-day rank of each FWI System output as a function of the output's respective value. We then used the fitted model to predict what the control-day rank of each fire-day output value would be. By subtracting predicted rank from the actual rank we were able to examine the rank shift across the percentile position of all recorded fires. Larger differences in the percentiles indicated stronger discriminatory power.

Our paired data structure provides a more powerful test of the discriminatory power of the FWI system outputs whilst examining all percentile values provides a more complete assessment of output discriminatory ability across all the fire weather conditions captured, independent of the scale and distribution of the index.

Finally, we used Thiel-Sen regression analyses to model the relationship between the index/code percentile scores on fire-days and the rank of each percentile value across the fire days (Eastaugh et al., 2012). The slope and intercept of the regression of percentile score on percentile rank were used as indicators of index/code performance where Eastaugh et al. (2012) claimed that a perfect discriminator would have a slope approaching zero and an intercept approaching 100. Smaller slopes and larger intercepts were therefore assumed to indicate better index performance. This method is, however, sensitive to both the overall number of days in the dataset and the number of fire days. This makes consistent interpretation of the results between 
261 different datasets difficult (see Supplementary Material Appendix II). This was not a particular

262 issue for us as we used a single dataset, but it did mean that comparisons of performance for all

263 fire days and large fire days were not equivalent, we therefore only examined the former. In

264 addition, with a very large number of fires, our data resulted in rather small slope values being

265 estimated which made it difficult to differentiate model performance using this metric. Thiel-Sen

266 regressions were fitted in R 3.1.2 using the "mblm" function of the mblm package (Komsta, 267 2015).

268 Having selected the best performing FWI system outputs, we used logistic regression to model 269 the probability of wildfire occurrence as a function of the chosen output and region, season, and 270 location (urban/rural). For this analysis we split the data into test and training datasets where the 271 test dataset was a $10 \%$ random sample of the full data and the training data the remaining $90 \%$.

272 Using the training data we initially fitted a full model which included all the main effects and all 273 two-way interactions. The full model was then simplified by deleting non-significant terms $(\mathrm{P}>$ 274 0.05) and examining the change in Akaike's Information Criterion (AIC). Interaction terms were 275 removed first and simplification stopped once deletions no-longer yielded further reductions in 276 AIC $>2$. Models were fitted using the "glm" function in R 3.1.2 and specifying a binomial 277 distribution and logit link function. Model performance was assessed using the test dataset by 278 calculating the c-index, area under the receiver operating characteristic (ROC) curve (Fawcett, 279 2006). ROC curves illustrate the relationship between the false positive and false negative rate as 280 the threshold probability value is changed. A c-index value of 0.5 indicates random predictions 281 whilst a value of 1.0 indicates perfect performance. We used the same procedures to examine the 282 ability of selected variables to discriminate between high magnitude fire days from normal (i.e. 
283 magnitude $<4$ ) fire days. This latter analysis examines the extent to which the independent

284 variables can model the probability of an observed ignition developing into a large fire.

285

286

287

288

289

290

291

292

293

294

295

296

297

298

299

300

301

302

304

303 Similar results were obtained from the percentile analysis which revealed ISI and FFMC as the

\section{RESULTS}

Wildfire occurrence varied substantially between regions and seasons with fires most common in the Highlands and during spring (Figure 1). Patterns of fire magnitude also varied greatly between regions with data from Grampian being somewhat unusual as very few low magnitude $(<3)$ events were reported (Figure 1). Fires were more common in rural locations as were large magnitude events. There were slightly less wildfires during the legal managed burning season compared to outside it. The end of the legal burning period in spring was marked by a slightly increased density of wildfire occurrences but this period was also associated with somewhat higher than average FFMC values. There was no obvious increased density of occurrences at the start of the burning season in autumn (see Figure S1 in Supplementary Tables and Figures). Larger magnitude ( $>3$ ) events occurred most frequently in spring and summer and in rural locations.

Initial screening of the FWI system outputs consistently showed the Initial Spread Index (ISI) and FFMC to have the greatest discriminatory power (Figure 2). Mahalanbois distances showed FFMC to be the best predictor overall, for large fires and for the Lothian and Highlands regions (Table 2). ISI performed best in the Dumfries and Grampian regions. FFMC performed best across all seasons except for the winter where the Duff Moisture Code (DMC) performed better. No output performed particularly well in summer, or in the Lothian region. best predictors of fire occurrence in general whilst FFMC was marginally better at predicting 
305 large fire events (Table 3). Differences in the results of Andrews et al.'s (2003) percentile and

306 our modified paired version were minimal. The analysis of percentile rank shift (Figure 3)

307 confirmed the strong performance of the FFMC and ISI. Both indices showed strongest

308 performance at intermediate levels of these outputs with discrimination declining at higher levels

309 of FFMC. The related DMC and BUI indices showed similar patterns in discriminatory ability

310 but considerably worse performance than the FFMC, ISI or FWI. During periods with the most

311 extreme fire weather $\left(>90^{\text {th }}\right.$ percentile) the DC appeared to provide marginally better

312 discrimination.

313 Thiel-Sen analysis yielded somewhat different results to the previous scoping methods. The

314 slopes of the regressions were all rather similar and close to zero due to the large number of days

315 in the whole dataset (Table 4). Overall ISI was rated as the best discriminator of wildfire

316 occurrence, but FFMC and FWI were more difficult separate with FWI having the better slope

317 and FFMC the better intercept.

318 We selected the FFMC and ISI as the two best performing outputs during scoping and these

319 were used to model the probability of wildfire occurrence. We also tested the ability of FFMC,

320 and ISI to discriminate between normal and high magnitude fire days. The final occurrence

321 model using FFMC $(\mathrm{AIC}=9389)$ had a c-index of 0.77 for the test dataset. The model included

322 the main effects of FFMC, urban/rural location, season and region. There were significant

323 interactions between FFMC and urban/rural location, FFMC and season and FFMC and region

324 (See Supplementary Tables). The ISI model $(\mathrm{AIC}=9429)$ had a c-index of 0.76 for the test

325 dataset. The model included the main effects of ISI, urban/rural location, season and region.

326 There were significant interactions between ISI and urban/rural location, ISI and season and ISI

327 and region. Full model results are reported in the Supplementary Tables. The modeled results 
328 (Figures 4 and 5) suggested higher probabilities of wildfire at low FFMC or ISI values in autumn

329 and winter and in urban areas. There was a relatively low probability of wildfire in Grampian at

330 low FFMC values compared to the other regions. In all regions wildfires occurred at noticeably

331 higher values of ISI in summer. The probability of wildfire increased rapidly at FFMC values $>$

33250 and is generally very high $(>80 \%)$ at ISI values $>2$.

333

334

335

336

337

338

339

340

341

342

343

344

345

346

347

348

349

FFMC and ISI had approximately equivalent ability to distinguish between high magnitude fire events and "normal" fire days with c-index values of 0.76 and 0.77 respectively. Their

performance in detecting large fires was also roughly equal during scoping. Overall we preferred the FFMC model for the sake of consistency and because it performed slightly better during the final modeling process. The final model included the main effects of FFMC, region and season and an interaction between season and FFMC (See Supplementary Tables; Figure 6).

\section{DISCUSSION}

Patterns of wildfire activity vary significantly across Scotland with the most wildfires recorded during the study period occurring in the Highlands and Islands region. However, the four different study regions differ substantially in both area and population meaning that whilst on a per area basis Highlands and Islands sees the least wildfires, per person it receives by far the most (Table 5). The opposite is true for the more densely populated L\&B region that includes the city of Edinburgh and its outlying towns and villages. The trends are likely to be driven in part by differences in climate, land-cover, land-management and burning practice. Much of sparselypopulated western Scotland is managed extensively for sheep and deer grazing and traditional burning practices are associated with relatively large and uncontrolled burns to improve forage quality (Hamilton 2000). Grampian is a key area for traditional moorland management for grouse 
350 shooting (Douglas et al. 2015) and it is noticeable that here, where intensive prescribed burning

351 occurs each spring, wildfires are more common. There are, however, also strong gradients in fuel

352 type and climate from west to eastern Scotland with the shrub-dominated moorland fuels and

353 drier climate of eastern Scotland making fire hazard somewhat higher. On a per area basis

354 wildfires were most common in Lothians and Borders. Though fire is used in the southern upland

355 ecosystems of the Scottish Borders, the dense population of the Lothians means a substantial

356 number of smaller urban-interface fires in, for example, stands of gorse (Ulex europaeus L.) may

357 account for a large number of these fires. Though, overall, fewer fires were recorded in urban

358 than rural locations (Figure 1) the total urban area is a small proportion of the land area of

359 Scotland.

360 The tentative conclusions we can draw above are somewhat dependent on the quality of the 361 data. Though broad locations for fires are recorded these often have low precision and little 362 supporting information such as the cause of the fire, area and predominant fuel type. Efforts to 363 improve the quality of data recording are underway (e.g. Gazzard, 2009) and, along with the 364 unification of Fire and Rescue Services, this may solve some of the issues. In this context it was 365 also noticeable that the wildfires recorded in Grampian, a core area for traditional managed 366 burning for red grouse, were nearly all of medium-high magnitude. There are a number of 367 possible explanations for this including that Grampian may tend to deploy more resources to 368 fires than other regions or that smaller ignitions may not have been recorded (perhaps because 369 land-managers tend to extinguish small wildfire themselves). If the latter is the case then the 370 incidence of fire occurrences has been underestimated there. Better collaboration between the 371 FRS and researchers is an urgent need across the UK and developing a robust fire danger rating 372 system will require better quality data than we had to work with here. 
373 Despite the broad spatial scale at which fire-weather forecasts were made, the FFMC and ISI

374 performed tolerably well as predictors of wildfire occurrence. Our results for Scotland are similar

375 to those found in other studies in the UK. Albertson et al. (2009), working in the Peak District

376 National Park, found that wildfire occurrence was positively related to maximum temperature,

377 reduced rainfall and days when visitor numbers were likely to be higher. Furthermore, de Jong et

378 al. (2015) used a percentile-based approach to assess the performance of the FWI System across

379 the UK and found large regional differences in the numeric values of code/index $99^{\text {th }}$ percentiles.

380 Their results also suggested that the FFMC and ISI held promise for forecasting wildfire activity.

381 de Jong et al.'s and our results are interesting as previous research on fire behaviour in heather-

382 dominated upland ecosystems in Scotland found little relationship between the outputs of the

383 FWI system and fire rate of spread and intensity (Davies et al., 2006). This may be because the

384 rapid moisture response times of fine, elevated, dead shrub and grass fuels mean standard forms

385 of the FWI system codes are not appropriate for predicting their FMC (Legg et al., 2007,

386 Anderson \& Anderson, 2010). Unlike in other European shrubland ecosystems (e.g. Castro et al.

387 2003, Pellizzaro et al. 2007) live fuel moisture is not adequately reflected by the DMC and DC

388 as physiological drought conditions are rare in Scotland's wet organic soils and moisture

389 dynamics are driven by seasonal variation in plant physiology (Davies et al. 2010). We have

390 little published information on the relationship between Molinia litter moisture content and fire

391 weather. As with Scottish shrub fuels, summer drought and "curing" of vegetation are not

392 particularly important - rather seasonal patterns of flammability are associated with the autumn-

393 die back of grasses in response to changes in day length (Salim et al. 1988). Notwithstanding

394 this, particularly high values of the DMC and DC may relate to the potential for smouldering of 
395 deeper duff and organic soil layers and thus higher severity fires (Davies et al. 2013, Davies et al.

396 2016b).

397 This begs the question of why is the FWI System able to predict wildfire occurrence but not fire

398 behaviour? One important reason is likely to be that, for safety reasons, experimental fires have

399 not been completed over a particularly wide range of fire weather conditions and thus exclude

400 those associated with wildfires. However, we posit that the particular structural characteristics of

401 moorland fuel types may also be important and that key variables governing fuelbed ignitability

402 and fire behaviour differ. This is similar to the conclusions of Alexander (2008) who suggested

403 that fuel moisture acted as an "on/off switch" in shrub fuel types. A key difference in Scottish

404 moorlands compared to other fire-prone regions is that vegetation often grows on saturated

405 organic soils or peat that, for much of the year, retain moisture contents high enough to prevent

406 their ignition. The heather canopy and Molinia litter are readily flammable despite the former

407 containing large proportions of live vegetation (Davies et al., 2008; Davies \& Legg, 2011;

408 Santana 2014). Moorland fuels have surface layers of shrubs and grass underlain by

409 pleurocapous mosses, Sphagnum spp. and plant litter. During typical managed burning activities,

410 and many wildfires, these fuels are often too wet to burn (Davies et al., 2016b). Critically

411 therefore, many fires only burn through the heather canopy or the Molinia litter and the high

412 moisture content of the moss and litter actually plays an important role in controlling the efficacy

413 of the traditionally-used "firebeaters" to control and extinguish burns. In the case of heather-

414 dominated fuels, and other shrublands (e.g. Anderson \& Anderson, 2009), their behaviour has

415 been viewed as akin to mini independent crown fires.

416 The flammability of the heather canopy and Molinia litter, and their ability to burn at high

417 intensities even under very low FFMC/ISI values (Davies et al., 2006), means that wildfire 
418 activity may often only be limited by the lack of a suitable ignition source. Ignition potential of

419 the heather canopy has been shown to be a function of the fuel moisture content of dead

420 vegetation in the lower canopy (Davies \& Legg 2011), whilst the most important controls on

421 managed fire behaviour appear to be fuel structure, wind speed and live fuel moisture content

422 (Davies et al. 2009a). Previous research has demonstrated that FMC also plays an important role

423 in determining fire behaviour in Molinia litter fuels (Hamilton 2000). The lack of a relationship

424 between observed fire behaviour and FWI System fire behaviour indices has been ascribed to the

425 poor predictive power of the underlying moisture codes at least for shrub fuels (Anderson \&

426 Anderson 2009, Davies e al. 2006).

427 However, moss and litter layers contain as much, if not more fuel, than surface layers (Davies

428 et al. 2008) and if flammable will contribute significantly to increases in fire rate of spread

429 (Davies \& Legg 2011), intensity and control difficulty. They and Molinia litter fuels have been

430 shown to be readily ignitable from small, smouldering ignition sources (Davies et al. 2009b)

431 when sufficiently dry. The probability of ignition of the heather canopy by such mechanisms

432 may be low, not only as such ignition sources are likely to fall through it into the moss and litter,

433 but also because rates of heat loss will be high, and contact between the ignition source and fuel

434 low, making successful ignition unlikely. Previous research (Legg et al. 2007, Grau et al. 2015)

435 has suggested that the FFMC is correlated with the moisture content of moss and litter fuels

436 possibly as they are similar in composition and structure to the forest litter layers for which the

437 FFMC was developed. Microclimatic conditions below heather or grass canopies may also

438 approximate those found on the forest floors for which the FFMC was designed.

439 Given the above, we can summarize a conceptual model of factors allowing the ignition of

440 wildfires in moorland fuels, and their prediction by the FWI System as follows: 
441

442

443

444

445

446

447

448

449

450

451

452

453

454

455

456

457

458

459

460

461

462

463

1. Accidental fires originate from weak ignition sources that are unlikely to ignite shrub canopies. They are thus primarily a function of the moisture content of the moss and litter layer. The moisture content of this layer is correlated with the FFMC in most seasons allowing it to predict ignition potential. In winter, during periods of reduced day-length, higher precipitation and cold temperatures, the DMC performs better as its slower response more adequately represent the longer rainless periods required for moss/litter flammability.

2. Moisture conditions suitable for ignition and spread of prescribed fires ignited by strong ignitions (e.g. from a drip-torch or deliberate arson attempts) are not well-represented by the FFMC due to canopy fuels' rapid moisture response times and the marginal fire weather conditions under which such fuels can burn. However, flammability of the moss/litter layer plays a role in fire controllability and is associated step-changes in fire behaviour. The FFMC thus detects periods when managed fires are more likely to escape control.

Our scoping studies and the logistic regression analyses also revealed that there was substantial spatial variation in fire risk in relation to fire weather between regions and seasons (Table 2, Figures 4-6). Wildfires were more likely in urban areas during low-moderate risk conditions but are less likely when wildfire risk is very high. Fires are also more likely during marginal conditions in winter and autumn. This would again seem to suggest that wildfires are strongly ignition limited. From Figure 1, wildfires appeared to be no more likely during the legal burning season than at other times but given this period includes the winter months, which are frequently very wet or have snow cover, the number of actual days conducive to fire may be somewhat limited and fire activity higher on a per burn day basis. Figure S2 also suggests a clustering of wildfire activity around the end of the burning season in spring. This may be partly caused apparently drier conditions during this period but human factors and management decisions may 
464 also be at play. Exploring this question will require a better knowledge of the relationship

465 between fire weather conditions and ignition potential (e.g. Tanskanen et al., 2005) and

466 collaborative work with fire managers that encourages them to report conditions under which

467 they face control difficulties.

468 The FFMC, ISI and, to a lesser extent FWI, were also able to discriminate between high

469 magnitude wildfires and smaller scale events fairly well. The modelled probability of an

470 occurring fire being "large" must be treated with caution as the model is dominated by the effect

471 of Region (see Supplementary Tables) which may be at least partly related to differences in the

472 completeness of fire recording between regions (Figure 1). The probability of a fire being large

473 was generally low, though higher in the more remote, northerly Grampian and Highlands regions

474 (Figure 6). The probability of a wildfire becoming a large may thus be a function of accessibility.

475 Remote fires of any size are less likely to be reported early and will be large by the time the Fire

476 and Rescue Services have arrived on the scene. Very few wildfires occur in winter, a time when

477 FFMC values are generally low, but for higher values of FFMC the probability of a large

478 wildfire was greatest during this season. The few large wildfires recorded during this period are

479 clustered towards the end of February when FFMC is beginning to increase (see Supplementary

480 Figure S2) and wildfire preparedness may be low.

481 Scotland remains some way off developing an operational fire danger rating system and the

482 difficulties encountered by countries with similar fuels and climates (e.g. Alexander, 2008)

483 means considerable research is needed. The need for a system is growing as climate change is

484 likely to increase the risk of both wildfires in general (e.g. Scholze et al., 2006, Sutherland et al.

485 2008) and severe, damaging fires associated with the smouldering of ground fuel layers and peat

486 (Maltby et al., 1990; Davies et al. 2013). Scotland currently lacks its own system and is not 
487 covered by the Met Office Fire Severity Index which provides a forecast of severe fire weather 488 conditions. Coarse-scale forecasts of the FWI system outputs are, however, available from the 489 European Forest Fire Information System (http://forest.jrc.ec.europa.eu/effis). Choosing an 490 appropriate index to forecast fire risk is complicated as different indices performed better in 491 different region, at different times of year and for different purposes. Further research using 492 longer spans of data are urgently needed and should also seek to link fire weather controls on 493 wildfire risk to an analysis of the spatial distribution of ignitions in relation to vegetation types 494 and anthropogenic activity (e.g. Oliveira et al., 2012; McMorrow \& Lindley, 2006). The FRS or 495 other relevant agencies must invest in research and provide a regular stream of fire data to researchers if they want to develop a robust system. We also urge the Met Office to provide UK wide forecasts of the actual FWI System outputs so managers can make informed decisions.

\section{CONCLUSIONS}

The wildfire probabilities we've presented must be treated with caution as they are only the probability of a reportable wildfire in the presence of an anthropogenic ignition (Finney, 2005).

In the absence of any other information they could, in conjunction with EFFIS forecasts, be used by managers and the FRS to provide some advance warning of the potential for increased wildfire activity. On the basis of our results we suggest the following rules of thumb: wildfire are generally $>60 \%$ during such periods (Figure 4) regions and seasons the probability of wildfire will be $>80 \%$ (Figure 5) 
508

509

510

511

512

513

514

- Managed burning be avoided and fire-fighting resources on stand-by when DMC $>60$ as, though these conditions are rare, nearly all days in our dataset associated with such conditions were fire rather than control days (Figure 2). Burns during such conditions are likely to have high fire severities.

- In northern Scotland the Fire and Rescue Services should be prepared for higher magnitude wildfire events when FFMC $>75$ as the probability of a wildfire being "large" increased steeply above this value (Figure 6)

\section{ACKNOWLEDGEMENTS}

We are indebted to the Scottish Fire and Rescue Service for the provision of their wildfire data. Karl Kitchen and Penny Marno of the Met Office facilitated access to the NWP weather data used to generate the FWI system outputs. Michael Bruce, Jeff Ord and Stuart Anderson offered many helpful insights. Wendy Anderson provided a detailed and constructive peer-review of the initial research report from which this paper developed. Paulo Fernandes and two anonymous reviewers provided many insightful comments which improved the paper.

\section{REFERENCES}

Acs S, Hanley N, Dallimer M, Gaston KJ, Robertson P, Wilson P, Armsworth PR. 2010. The effect of decoupling on marginal agricultural systems: Implications for farm incomes, land use and upland ecology. Land Use Policy 27:550-563.

Albertson K, Aylen J, Cavan G, McMorrow J. 2009. Forecasting the outbreak of moorland wildfires in the English Peak District. Journal of Environmental Management 90:2642-2651. 
528 Aldhous JR, Scott AHA. 1993. Forest fire protection in the UK: experience in the period 1950-

529 1990. Commonwealth Forestry Review 72:39-47.

530 Alexander ME. 2008. Proposed revision of fire danger class criteria for forest and rural areas in

531 New Zealand. 2nd Edition. National Rural Fire Authority, Wellington, in association with Scion,

532 Rural Fire Research Group, Christchurch, New Zealand. Available at:

533 http://www.scionresearch.com/ data/assets/pdf file/0012/4620/Fire-Danger-Classification-

534 Criteria-reprint final-corr.pdf (accessed 14 August 2015).

535 Allison BJ. 1954. Lightning and forest fires at Rosedale Tarn. Journal of the Forestry

536 Commission 23:65-66.

537 Anderson SAJ, Anderson WR. 2010. Ignition and fire spread thresholds in gorse (Ulex

538 europaeus). International Journal of Wildland Fire 19:589-598.

539 Anderson SAJ, Anderson WR. 2009. Predicting the elevated dead fine fuel moisture content in

540 gorse (Ulex europaeus L.) shrub fuels. Canadian Journal of Forest Research 39:2355-2368.

541 Andrews PL, Loftsgaarden DO, Bradshaw LS. 2003. Evaluation of fire danger rating indexes

542 using logistic regression and percentile analysis. International Journal of Wildland Fire 12:213543226.

544 Archibald S, Lehmann CER, Gómez-Dans JL, Bradstock RA. 2013. Defining pyromes and 545 global syndromes of fire regimes. PNAS 110: 6442-6447.

546 Backshall J, Manley J, Rebance M. (Eds.). 2001. The Upland Management Handbook. English

547 Nature, Peterborough. 
548 Beccari A, Borgoni R, Cazzuli O, Grimaldelli R. 2015. Use and performance of the Forest Fire

549 Weather Index to model the risk of wildfire occurrence in the Alpine region. Environment and

550 Planning B: Planning and Design 43: 772-790.

551 Castro FX, Tudela A, Sebastià MT. 2003. Modeling moisture content in shrubs to predict fire

552 risk in Catalonia (Spain), Agricultural and Forest Meteorology 116: 49-59.

553 DaCamara CC, Calado TJ, Ermida SL, Trigo IF, Amraoui M, Turkman KF. 2014. Calibration of

554 the Fire Weather Index over Mediterranean Europe based on fire activity retrieved from MSG

555 satellite imagery. International Journal of Wildland Fire 23: 945-958.

556 Davies GM, Legg CJ. 2011. Fuel moisture thresholds in the flammability of Calluna vulgaris.

557 Fire Technology 47:421-436.

558 Davies GM, Legg CJ, Smith AA, MacDonald A. 2006. Developing shrub fire behaviour models

559 in an oceanic climate: Burning in the British Uplands. Forest Ecology and Management

560 234:S107.

561 Davies GM, Legg CJ, Hamilton A, Smith AA. 2008. Using visual obstruction to estimate

562 heathland fuel load and structure. International Journal of Wildland Fire 17:380-389.

563 Davies GM, Legg CJ, Hadden R, Rein G. 2009. The effect of moisture content on fire initiation

564 from smoldering ignition sources. Northwest Scientific Association $81^{\text {st }}$ Annual Meeting.

565 University of Washington, Seattle, Washington 25-28 March 2009. Available at:

566 http://www.northwestscience.org/Resources/Final\%20Annual\%20Meeting\%20Abstracts\%20and

567 \%20Programs/2009\%20NWSA\%20Program\%20and\%20Abstracts.pdf (accessed $18^{\text {th }}$ September 568 2016). 
569 Davies GM, O'Hara R, Smith AA, MacDonald A, Legg CJ. 2010. Winter desiccation and rapid

570 changes in the live fuel moisture content of Calluna vulgaris. Plant Ecology and Diversity 3:

571 289-299.

572 Davies GM, Gray A, Rein G, Legg CJ. 2013. Peat consumption and carbon loss due to

573 smouldering wildfire in a temperate peatland. Forest Ecology and Management 308:136-144.

574 Davies GM, Kettridge N, Stoof CR, Gray A, Ascoli D, Fernandes PM, Marrs R, Allen KA,

575 Doerr SH, Clay G, McMorrow J, Vigdis V. 2016a. The role of fire in U.K peatland and

576 moorland management; the need for informed, unbiased debate. Philosophical Transactions of

577 the Royal Society B 371:20150342.

578 Davies GM, Domenech R, Gray A, Johnston PCD. 2016b. Vegetation structure and fire weather 579 influence variation in burn severity and fuel consumption during peatland wildfires.

580 Biogeosciences 13:389-398.

581 de Jong MC, Wooster MJ, Kitchen K, Manley C, Gazzard R, McCall FF. 2016. Calibration and 582 evaluation of the Canadian Forest Fire Weather Index (FWI) System for improved wildland fire 583 danger rating in the United Kingdom. Natural Hazards and Earth System Sciences 16:1217-1237.

584 Dimitrakopoulos AP, Bemmerzouk AM, Mitsopoulos ID. 2011. Evaluation of the Canadian fire 585 weather index system in an eastern Mediterranean environment. Meteorological Applications 18: $58683-93$.

587 Doerr SH, Santín C. 2016. Global trends in wildfire and its impacts: perceptions versus realities 588 in a changing world. Philosophical Transactions of the Royal Society B 371: 20150345 
589 Nature 460, 616-619 (30 July 2009) | doi:10.1038/nature08216; Received 30 January 2009;

590 Accepted 16 June 2009

591 Dorrepaal E, Toet S, van Logtestijn RSP, Swart E, van de Weg MJ, Callaghan TV, Aerts R.

592 2009. Carbon respiration from subsurface peat accelerated by climate warming in the subarctic.

593 Nature 460: 616-619

594 Douglas DJT, Buchanan GM, Thompson P, Amar A, Fielding DA, Redpath SM, Wilson JD.

595 2015. Vegetation burning for game management in the UK uplands is increasing and overlaps

596 spatially with soil carbon and protected areas. Biological Conservation 191:243-250.

597 Eastaugh CS, Arpaci A, Vacik H. 2012. A cautionary note regarding comparisons of fire danger 598 indices. Natural Hazards and Earth System Sciences 12:927-934.

599 Farmer R. 2003. Fires on the FC estate. Paper for the Forestry Commission National Committee 600 for Wales 29th August 2003.

601 Fawcett T. 2006. An introduction to ROC analysis. Pattern Recognition Letters 27: 861-874.

602 Finney M. 2005. The challenge of quantitative risk analysis for wildland fire. Forest Ecology and 603 Management 211:97-108.

604 Gazzard R. 2009. United Kingdom Vegetation Fire Standard. Forestry Commission, United 605 Kingdom. Available at:

606 http://www.forestry.gov.uk/pdf/UKVFS_August_2009.pdf/\$FILE/UKVFS_August_2009.pdf 607 (accessed 14 August 2015). 
608 Gazzard R, McMorrow J, Aylen J. 2016. Wildfire policy and management in England: an

609 evolving response from Fire and Rescue Services, forestry and cross-sector groups.

610 Philosophical Transactions of the Royal Society B 371: 20150341.

611 Glaves DJ, Morecroft M, Fitzgibbon C, Lepitt P, Owen M, Phillips S. 2013. Natural England

612 Review of Upland Evidence 2012 - The effects of managed burning on upland peatland

613 biodiversity, carbon and water. Natural England Evidence Review, Number 004. Natural

614 England, Exeter, United Kingdom.

615 Grau R, Davies GM, Waldron S, Legg CJ. 2015. Moisture codes of the Canadian Fire Weather

616 Index system could be used to forecast the flammability of key moorland fuels. UK Wildfire

617 Conference. Available at: www.firescotland.gov.uk/media/901438/Grau Canadian

618 FWI_Moisture codes_moorland fuels_2015.pdf (accessed 21 September 2016).

619 Hamilton A. 2000. The characteristics and effects of management fire on blanket-bog vegetation

620 in north-west Scotland. PhD thesis, The University of Edinburgh.

621 Hancock MH, Summers RW, Amphlett A, Willi J. 2009. Testing prescribed fire as a tool to

622 promote Scots pine Pinus sylvestris regeneration. European Journal of Forest Research 128:319-

623333.

624 Hudson PJ. 1992. Grouse in Space and Time. Game Conservancy Ltd, Fordingbridge, United

625 Kingdom.

626 Jenkins GJ, Murphy JM, Sexton DMH, Lowe JA, Jones P, Kilsby CG. 2009. UK Climate

627 Projections: Briefing report. Met Office Hadley Centre, Exeter, United Kingdom. 
628 Joint Arson Group. 2007. Wales Arson Reduction Strategy. Report of the Joint Arson Group.

629 Welsh Assembly Government, Cardiff, Wales, United Kingdom. Available at:

630 http://gov.wales/dsjlg/publications/fire/arsonstrategy/walesarsonreductionstrategye?status=gxbqa

631 mrvi $\% 252525253 \mathrm{f} \% 252525253 \mathrm{f} \% 252525253 \mathrm{f} \% 252525253 \mathrm{f} \&$ lang=en (accessed 08 January

632 2016).

633 Komsta L. 2013. mblm: Median-Based Linear Models. R package version 0.12. Available at:

634 http://CRAN.R-project.org/package=mblm (accessed 14 August 2015).

635 Krawchuk MA, Moritz MA. 2014. Burning issues: statistical analyses of global fire data to 636 inform assessments of environmental change. Environmetrics 25: 472-481.

637 Legg CJ, Davies GM, Kitchen K, Marno P. 2007. Developing a Fire Danger Rating System for 638 the UK: FireBeaters Phase I final report. Report to the Scottish Wildfire Forum. Available at: 639 https://www.era.lib.ed.ac.uk/handle/1842/3011 (accessed 14 August 2015).

640 Maltby E, Legg CJ, Proctor MCF. 1990. The ecology of severe moorland fires on the North York 641 Moors. Effects of the 1976 fires, and subsequent surface and vegetation development. Journal of 642 Ecology 78:490-518.

643 McMorrow J, Lindley S. 2006. Modelling the Spatial Risk of Moorland Wildfire. Final report, 644 Moors for the Future small grant A79419_spg17. University of Manchester, Manchester, United 645 Kingdom. Available at:

646 http://www.moorsforthefuture.org.uk/sites/default/files/documents/2006_McMorrow\%20et $\% 20 \mathrm{a}$

647 1_MFF\%20Fire\%20risk\%20map.pdf (accessed 14 August 2015). 
648 Murphy PM, Mudd JP, Stocks BJ, Kasischke ES, Barry D, Alexander ME, French NHF. 2000. 649 Historical fire records in the North American boreal forest. Fire, Climate Change, and Carbon 650 Cycling in the Boreal Forest. Ecological Studies 138: 274-288.

651 Oliveira S, Oehler F, San-Miguel-Ayanz J, Camia A, Pereira JMC. 2012. Modeling spatial 652 patterns of fire occurrence in Mediterranean Europe using Multiple Regression and Random 653 Forest. Forest Ecology and Management 275:117-129.

654 Padilla M, Vega-García C. 2011. On the comparative importance of fire danger rating indices 655 and their integration with spatial and temporal variables for predicting daily human-caused fire 656 occurrences in Spain. International Journal of Wildland Fire 20: 46-58.

657 Pellizzaro G, Cesaraccio C, Duce P, Ventura A, Zara P. 2007. Relationships between seasonal 658 patterns of live fuel moisture and meteorological drought indices for Mediterranean shrubland 659 species. International Journal of Wildland Fire 16: 232-241.

660 Peterson DL, Halofsky JE, Johnson MC. 2011. Managing and Adapting to Changing Fire 661 Regimes in a Warmer Climate. In: McKenzie D, Miller C, Falk DA (eds.) The Landscape 662 Ecology of Fire. Ecological Studies 213. London, Springer.

663 R Core Team. 2014. R: A language and environment for statistical computing. R Foundation for 664 Statistical Computing, Vienna, Austria. Available at: http://www.R-project.org (accessed 14 665 August 2015).

666 Salim KA, Carter PL, Shaw S, Smith CA. 1988. Leaf abscission zones in Molinia caerulea (L.) 667 Moench, the purple moor grass. Annals of Botany 62: 429-434. 
668 Santana VM, Marrs RH. 2014. Flammability properties of British heathland and moorland 669 vegetation: models for predicting fire ignition. Journal of Environmental Management 139:8867096.

671 Scholze M, Knorr W, Arnell NW, Prentice IC. 2006. A climate-change risk analysis for world 672 ecosystems. PNAS 103: 13116-13120.

673 Simpson CC, Pearce HG, Sturman AP \& Zawar-Reza P. 2014. Verification of WRF modelled 674 fire weather in the 2009-10 New Zealand fire season. International Journal of Wildland Fire $675 \quad 23: 34-45$.

676 Stephens SL, Agee JK, Fulé PZ, North MP, Romme WH, Swetnam TW, Turner MG. 2013. 677 Managing forests and fire in changing climates. Science 342: 41-42.

678 Sutherland WJ, Bailey MJ, Bainbridge IP, Brereton T, Dick JAT, Drewitt J, Dulvy NK, Dusic 679 NR, Freckleton RP, Gaston KJ, Gilder PM, Green RE, Heathwaite AL, Johnson SM, Macdonald 680 DW, Mitchell R, Osborn D, Owen RP, Pretty J, Prior SV, Prosser H, Pullin AS, Rose P, Stott A, 681 Tew T, Thomas CD, Thompson DBA, Vickery JA, Walker M, Walmsley C, Warrington S, 682 Watkinson AR, Williams RJ, Woodroffe R, Woodroof HJ. 2008. Future novel threats and 683 opportunities facing UK biodiversity identified by horizon scanning. Journal of Applied Ecology $684 \quad 45: 821-833$.

685 Tanskanen H, Venäläinen A. 2008: The relationship between fire activity and fire weather 686 indices at different stages of the growing season in Finland. Boreal Environmental Research 13: $687 \quad 285-302$. 
688 Tanskanen H, Venäläinen A, Puttonen P, Granström A. 2005. Impact of stand structure on 689 surface fire ignition potential in Picea abies and Pinus sylvestris forests in southern Finland.

690 Canadian Journal of Forest Research 35:410-420.

691 Thompson DBA, MacDonald AJ, Marsden JH, Galbraith CA. 1995. Upland heather moorland in 692 Great Britain - a review of international importance, vegetation change and some objectives for 693 nature conservation. Biological Conservation 71:163-178.

694 Turetsky MR, Benscoter B, Page S, Rein G, van der Werf GR \& Watts A. 2015. Global 695 vulnerability of peatlands to fire and carbon loss. Nature Geoscience 8: 11-14.

696 Van Wagner CE, Pickett TL. 1985. Equations and FORTRAN program for the Canadian Forest 697 Fire Weather Index System. Forestry Technical Report 33. Canadian Forestry Service, Petawawa 698 National Forestry Institute, Chalk River, Ontario.

699 Webb NR. 1998. The traditional management of European heathlands. Journal of Applied 700 Ecology 35: 987-990.

701 Viegas DX, Bovio G, Ferreira A, Nosenzo A, Sol B. 1999. Comparative study of various 702 methods of fire danger evaluation in southern Europe. International Journal of Wildland Fire $7039: 235-246$. 


\section{TABLES}

706 Table 1: Description of the fuel moisture codes and fire behavior indices of the Canadian Fire

707 Weather Index System

\begin{tabular}{ll}
\hline \multicolumn{1}{c}{ Code/Index } & \multicolumn{1}{c}{ Description } \\
\hline Fine Fuel Moisture Code (FFMC) & $\begin{array}{l}\text { Moisture content of cured leaves, needles and small } \\
\text { dead twigs on the forest floor } \\
\text { Moisture content of loosely-compacted, partially } \\
\text { decomposed needle litter } \\
\text { Duff Moisture Code (DMC) }\end{array}$ \\
Moisture content of deep layers of compact humus and \\
organic matter
\end{tabular}

708

709 
710 Table 2: Mahalanobis distances describing the discriminatory power of moisture codes and fire

711 weather indices for the wildfire dataset as a whole, for large fires only and for each region and

712 season in the data. The best performing code or index is shown in bold.

\begin{tabular}{llllllll}
\hline & & FFMC & DMC & DC & BUI & ISI & FWI \\
\hline & Overall & $\mathbf{0 . 6 6}$ & 0.20 & 0.00 & 0.16 & 0.58 & 0.30 \\
& & & & & & \\
\hline \multirow{2}{*}{ Region } & Large fires & $\mathbf{1 . 1 6}$ & 0.32 & 0.01 & 0.23 & 1.06 & 0.52 \\
& Dumfries & 0.76 & 0.38 & 0.01 & 0.29 & $\mathbf{0 . 8 0}$ & 0.52 \\
& Highlands & $\mathbf{0 . 8 4}$ & 0.15 & 0.00 & 0.10 & 0.68 & 0.23 \\
& Lothian & $\mathbf{0 . 3 9}$ & 0.12 & 0.00 & 0.10 & 0.34 & 0.19 \\
& & & & & & & \\
\hline \multirow{2}{*}{ Season } & Spring & $\mathbf{1 . 0 9}$ & 0.65 & 0.03 & 0.61 & 0.98 & 0.63 \\
& Summer & $\mathbf{0 . 3 5}$ & 0.21 & 0.01 & 0.21 & 0.33 & 0.32 \\
& Autumn & $\mathbf{0 . 5 6}$ & 0.45 & 0.10 & 0.46 & 0.54 & 0.52 \\
& Winter & 0.61 & $\mathbf{0 . 8 2}$ & 0.01 & 0.62 & 0.78 & 0.68 \\
& & & & & & & \\
\hline
\end{tabular}

713

714 
716 Table 3: Above: Fire Weather Index system code and index values for the $25^{\text {th }}, 50^{\text {th }}$ and $90^{\text {th }}$

717 percentiles for control days / combined fire and control days ('all' days); Below: Difference

718 between the fire day percentile and the control/all day percentile and for (A) all fire days and (B)

719 large fire days. Values indicating the best performing code/index for each percentile are shown

720 in bold

\begin{tabular}{cccccccc}
\hline $\begin{array}{c}\text { All/Control Day } \\
\text { Percentile }\end{array}$ & FFMC & DMC & DC & BUI & ISI & FWI \\
\hline $25^{\text {th }}$ & $48.0 / 57.9$ & $1.7 / 2.8$ & $35.4 / 45.7$ & $2.6 / 4.5$ & $0.1 / 0.4$ & $0.1 / 0.2$ \\
$50^{\text {th }}$ & $64.4 / 74.4$ & $6.0 / 9.7$ & $200.1 / 199.8$ & $10.6 / 15.8$ & $0.6 / 0.9$ & $0.4 / 0.7$ \\
$90^{\text {th }}$ & $82.8 / 84.6$ & $30.3 / 33.9$ & $533.9 / 545.4$ & $51.2 / 57.1$ & $1.8 / 2.3$ & $4.5 / 6.3$
\end{tabular}

\begin{tabular}{ccccccc}
\hline (A) & \multicolumn{6}{c}{ Fire Day difference from control/all day percentile } \\
Percentile & FFMC & DMC & DC & BUI & ISI & FWI \\
\hline $25^{\text {th }}$ & $\mathbf{2 1 / 1 5}$ & $16 / 9$ & $7 / 3$ & $16 / 8$ & $\mathbf{2 1 / 1 5}$ & $20 / 14$ \\
$50^{\text {th }}$ & $\mathbf{3 3 / 1 8}$ & $21 / 11$ & $0 / 0$ & $19 / 10$ & $\mathbf{3 3} / 17$ & $30 / 15$ \\
$90^{\text {th }}$ & $\mathbf{2 2 / 6}$ & $7 / 3$ & $5 / 3$ & $6 / 3$ & $\mathbf{2 2 / 6}$ & $16 / 5$ \\
\hline
\end{tabular}

\begin{tabular}{ccccccc}
\hline (B) & \multicolumn{6}{c}{ Large Fire Day difference from control/all day percentile } \\
Percentile & FFMC & DMC & DC & BUI & ISI & FWI \\
\hline $25^{\text {th }}$ & $\mathbf{2 4 / 2 0}$ & $20 / 13$ & $5 / 1$ & $18 / 10$ & $\mathbf{2 4 / 2 0}$ & $23 / 19$ \\
$50^{\text {th }}$ & $\mathbf{4 3 / 2 8}$ & $21 / 12$ & $-4 /-4$ & $18 / 10$ & $42 / \mathbf{2 9}$ & $37 / 22$ \\
$90^{\text {th }}$ & $31 / 11$ & $11 / 7$ & $5 / 3$ & $11 / 6$ & $\mathbf{3 4 / 1 4}$ & $21 / 10$ \\
\hline
\end{tabular}


723 Table 4: Sumary of Thiel-Sen analyses on the discriminatory power of codes and indices of the

724 Canadian Fire Weather Index System. The columns Rank Intercept and Rank Slope show the 725 rank order of code/index performance according to each of the metrics.

\begin{tabular}{|c|c|c|c|c|}
\hline Fire weather variable & Intercept & Slope & Rank Intercept & Rank Slope \\
\hline FFMC & 23.27 & 0.019 & 2 & 3 \\
\hline $\mathrm{DMC}$ & 15.65 & 0.020 & 4 & 5 \\
\hline $\mathrm{DC}$ & -0.12 & 0.023 & 6 & 6 \\
\hline BUI & 13.33 & 0.020 & 5 & 4 \\
\hline ISI & 23.37 & 0.019 & 1 & 2 \\
\hline FWI & 22.04 & 0.019 & 3 & 1 \\
\hline
\end{tabular}

726

727

728 
729 Table 5: Regional variation in wildfire activity during the study period ( $1^{\text {st }}$ January $2003-15^{\text {th }}$

730 March 2007) in relation to land-surface area and population. The time-span of the L\&B data was

7317 months shorter than the other regions so these figures are conservative in comparison to the

732 other regions.

\begin{tabular}{lll}
\hline Region & Wildfires per km & Wildfires per person \\
\hline Dumfries \& Galloway & 0.07 & 0.003 \\
Grampian & 0.10 & 0.002 \\
Highlands \& Islands & 0.05 & 0.007 \\
Lothian \& Borders & 0.18 & 0.001 \\
\hline
\end{tabular}

733 


\section{FIGURE LEGENDS}

735 Figure 1: Spatial and temporal variation in the occurrence of Scottish wildfires according to,

736 former Fire Brigade Region (top-left); urban and rural locations, where urban locations are

737 within $10 \mathrm{~km}$ of one of Scotland's 100 larges towns and cities (top-right); season (bottom-left);

738 and whether the fire occurred during the legal muirburn season (bottom-right). Colours relate to

739 fire magnitude, grey $=0$, cream $=1$, yellow $=2$, orange $=3$, dark orange $=4$, red $=5$.

740 Figure 2: Wildfire occurrence in four regions of Scotland in relation to key moisture codes and

741 fire weather indices of the Canadian Fire Weather Index System. The histograms (left) show fire

742 occurrence in relation to (from top), FFMC, DMC, ISI and FWI. The distribution of moisture

743 code / fire behavior index occurrences on control days is shown as a shaded polygon. The plots

744 on the right show the conditional probability of a wildfire occurring across the range of FFMC,

745 DMC, ISI and FWI in the data. The distribution of fire occurrences (red) and control days (grey)

746 are also shown. Fire and control occurrences have been "jittered" on the y-axis.

747 Figure 3: Rank shift between fire and control days for FWI system outputs percentiles for

748 wildfires in Scotland. The analysis compares the difference in rank between that recorded on a

749 fire day and the rank of an equivalent value on control days. Higher values represent greater

750 discriminatory power. Each output is shown in a different colour/style: FFMC = solid black;

751 DMC $=$ solid orange; DC $=$ solid red; ISI $=$ dashed orange; BUI $=$ dashed red; and FWI = dashed

752 black.

753 Figure 4: Modelled probability of wildfires in Scotland as a function of FFMC and season for

754 rural (solid lines) and urban (<10 km from one of Scotland's 100 largest towns or cities; dotted 
755 lines) locations across four regions of Scotland. Green $=$ spring, dark green $=$ summer, blue $=$ 756 autumn, grey $=$ winter.

757 Figure 5: Modelled probability of wildfires in Scotland as a function of ISI and season for rural 758 (solid lines) and urban (<10 km from one of Scotland's 100 largest towns or cities; dotted lines) 759 locations across four regions of Scotland. Green = spring, dark green $=$ summer, blue $=$ autumn, 760 grey $=$ winter.

761 Figure 6: Modelled probability of observed wildfires in Scotland being "large" as a function of

762 FWI and season for rural (solid lines) and urban $(<10 \mathrm{~km}$ from one of Scotland's 100 largest

763 towns or cities; dotted lines) locations across four regions of Scotland. Green = spring, dark

764 green $=$ summer, blue $=$ autumn, grey $=$ winter.

765

766 

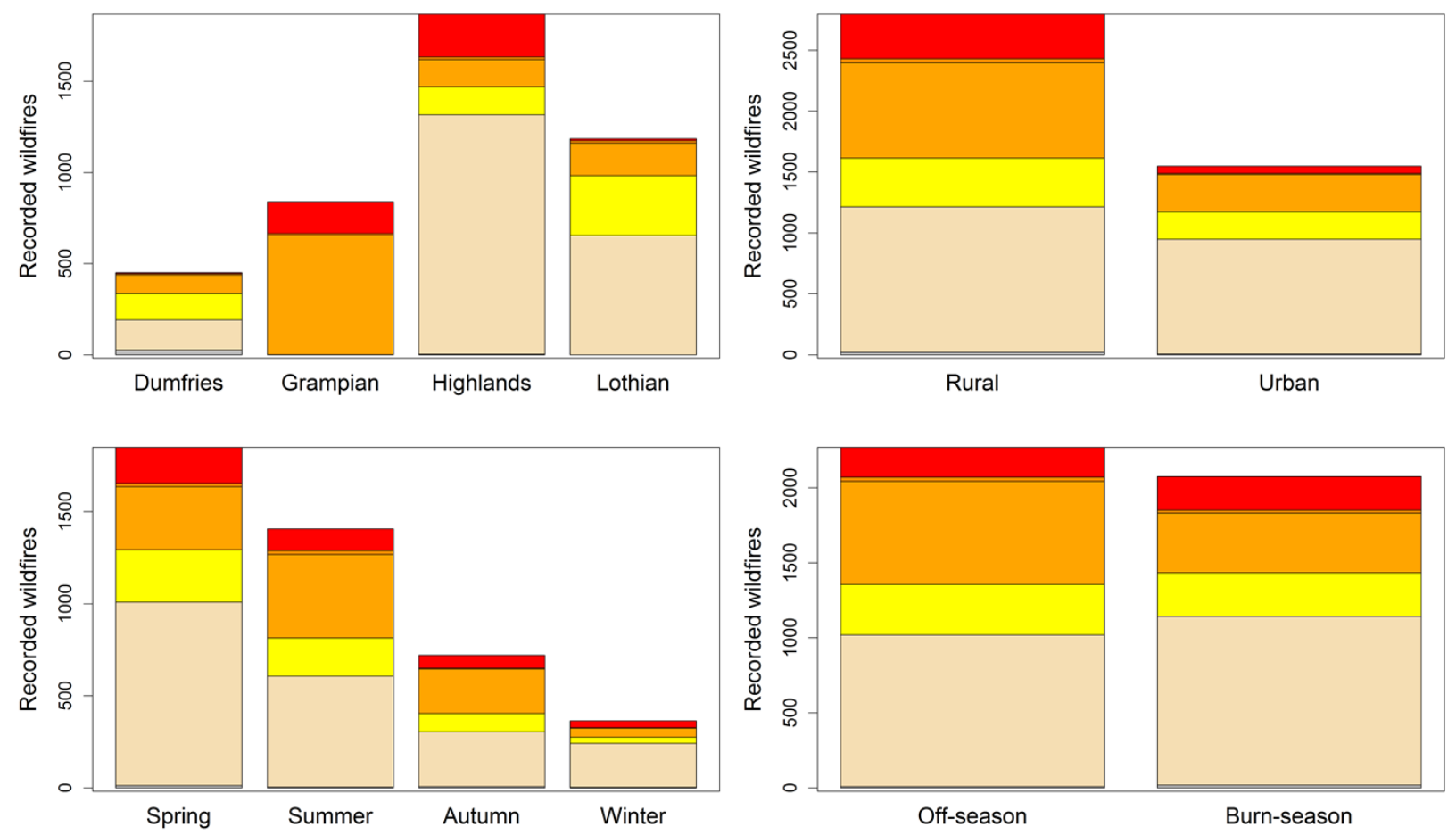

767

768 Figure 1: Spatial and temporal variation in the occurrence of Scottish wildfires according to,

769 former Fire Brigade Region (top-left); urban and rural locations, where urban locations are

770 within $10 \mathrm{~km}$ of one of Scotland's 100 larges towns and cities (top-right); season (bottom-left);

771 and whether the fire occurred during the legal muirburn season (bottom-right). Colours relate to

772 fire magnitude, grey $=0$, cream $=1$, yellow $=2$, orange $=3$, dark orange $=4$, red $=5$. 

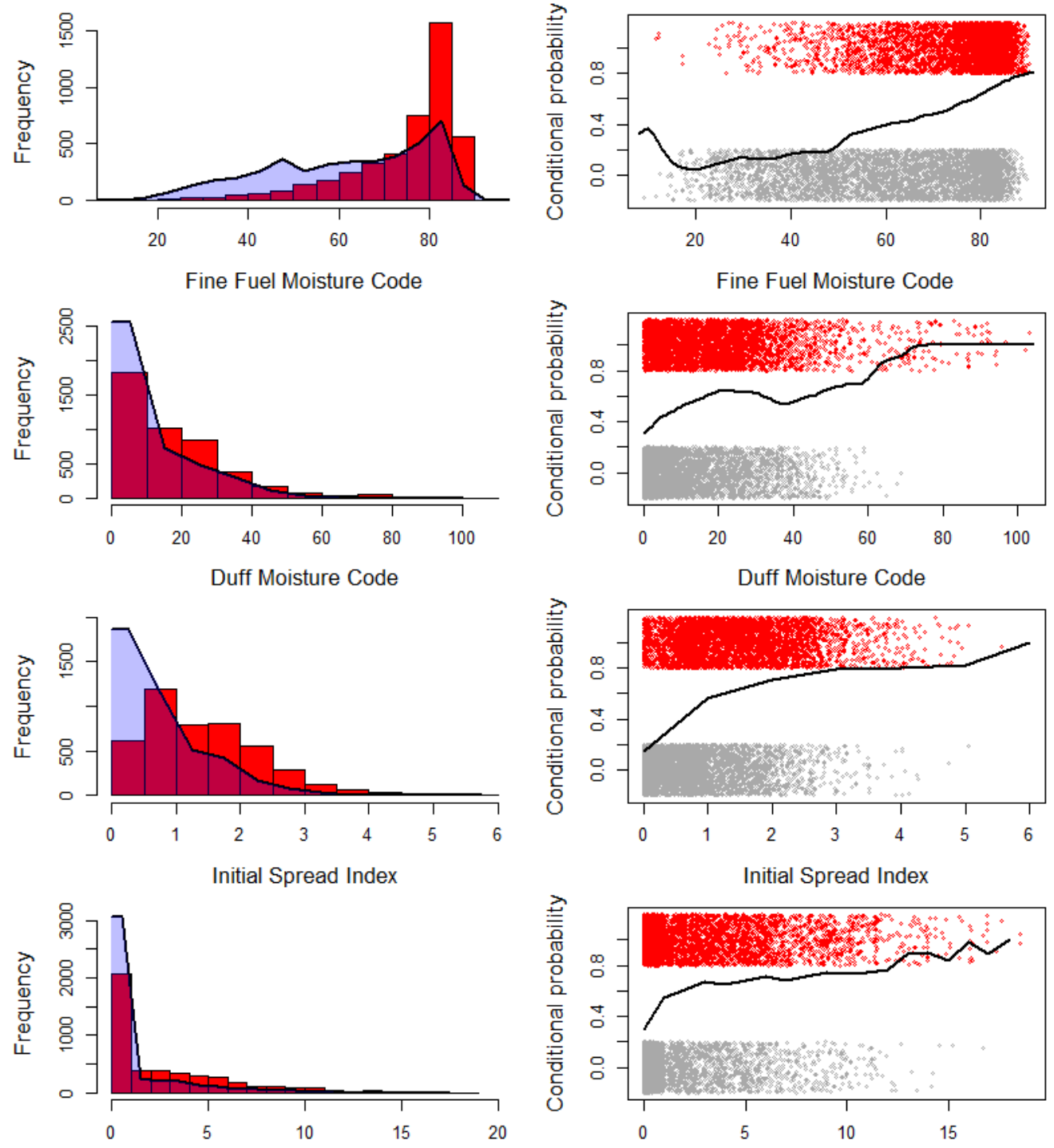

Fire Weather Index

774 Figure 2: Wildfire occurrence in four regions of Scotland in relation to key moisture codes and

775 fire weather indices of the Canadian Fire Weather Index System. The histograms (left) show fire

776 occurrence in relation to (from top), FFMC, DMC, ISI and FWI. The distribution of moisture

777 code / fire behavior index occurrences on control days is shown as a shaded polygon. The plots

778 on the right show the conditional probability of a wildfire occurring across the range of FFMC,

779 DMC, ISI and FWI in the data. The distribution of fire occurrences (red) and control days (grey)

780 are also shown. Fire and control occurrences have been "jittered" on the y-axis. 


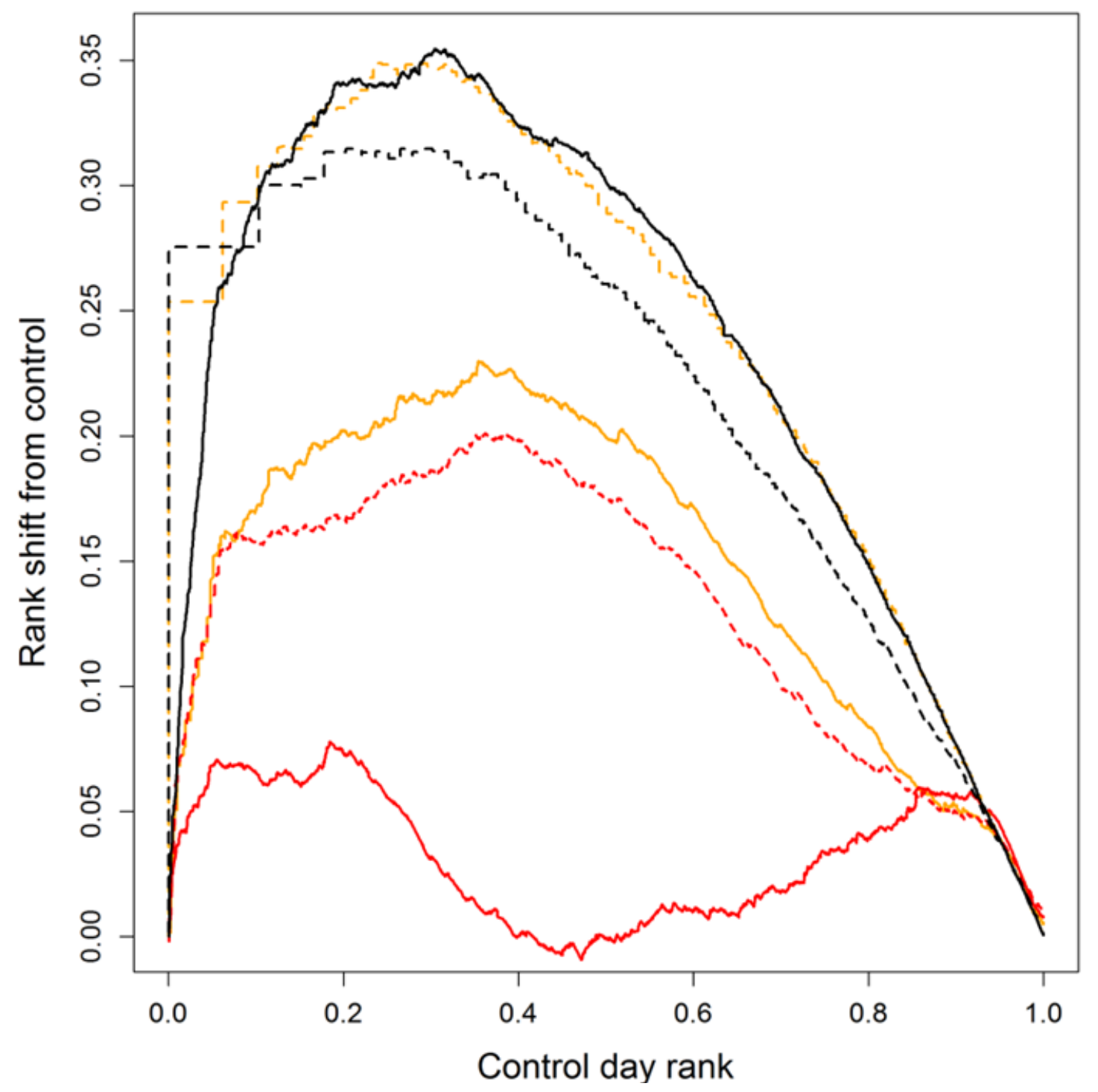

782

Figure 3: Rank shift between fire and control days for FWI system outputs percentiles for wildfires in Scotland. The analysis compares the difference in rank between that recorded on a fire day and the rank of an equivalent value on control days. Higher values represent greater discriminatory power. Each output is shown in a different colour/style: FFMC = solid black; $\mathrm{DMC}=$ solid orange; $\mathrm{DC}=$ solid red $; \mathrm{ISI}=$ dashed orange; $\mathrm{BUI}=$ dashed red; and FWI = dashed black. 

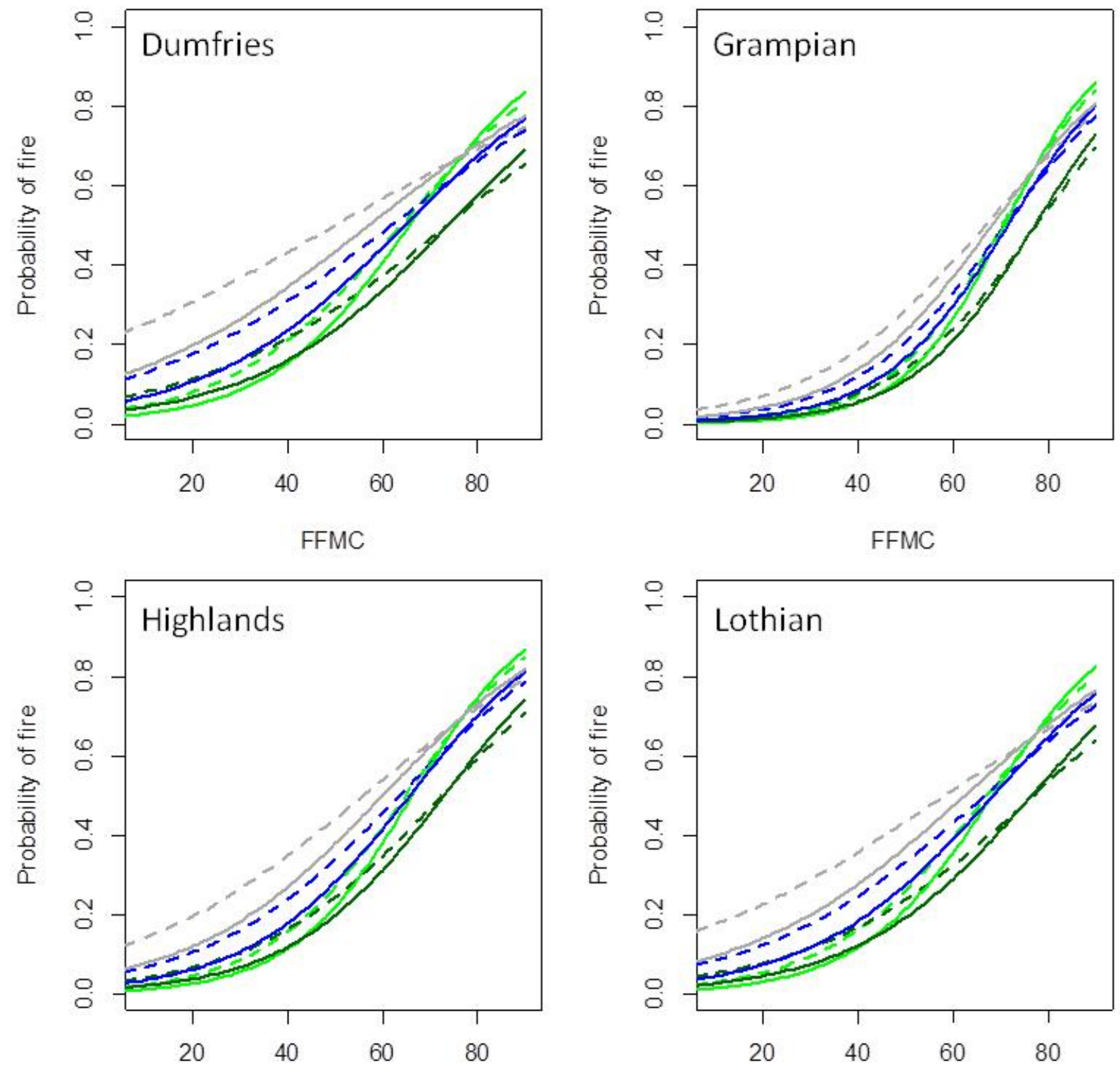

788

FFMC

FFMC

789

790

791

792 autumn, grey $=$ winter. 


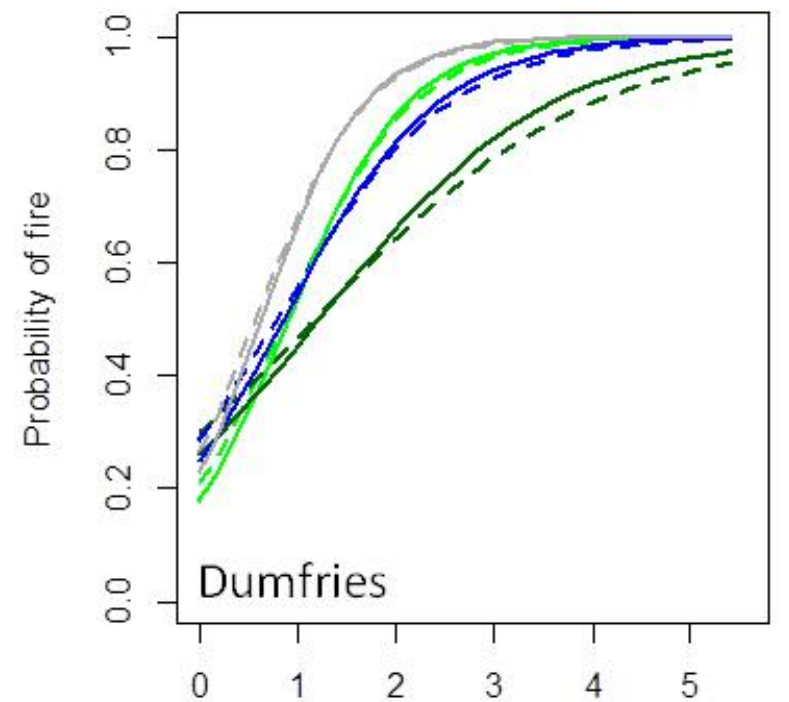

ISI

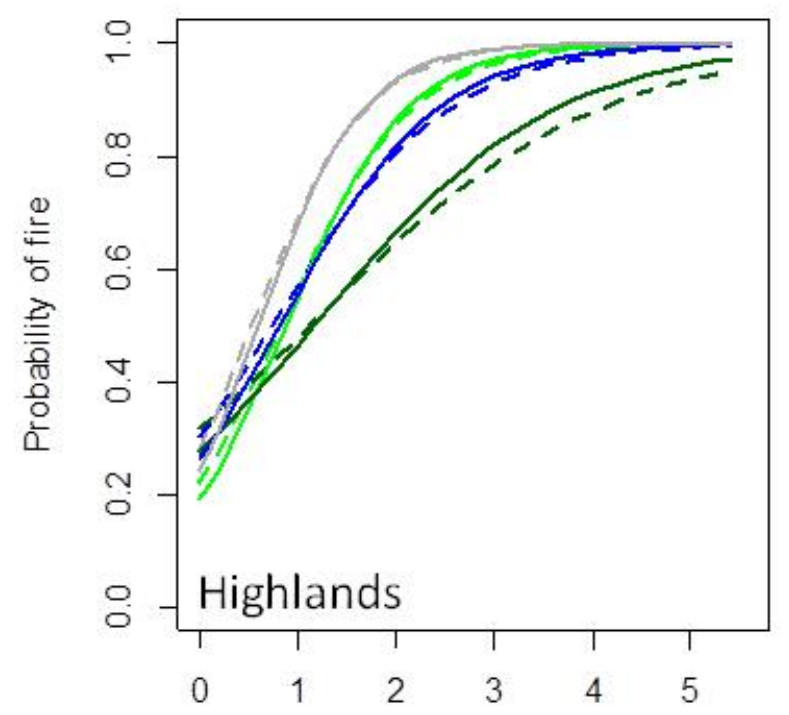

ISI

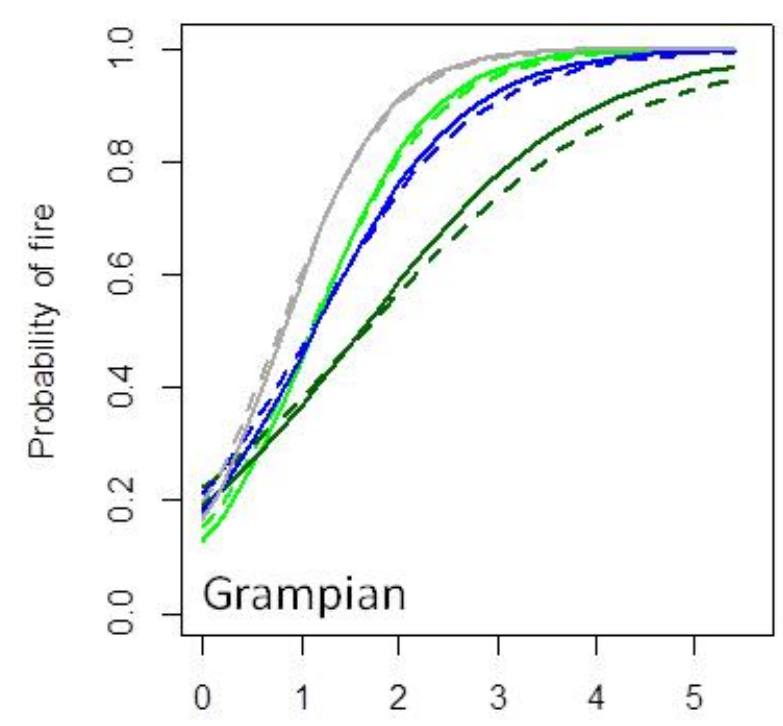

$|S|$

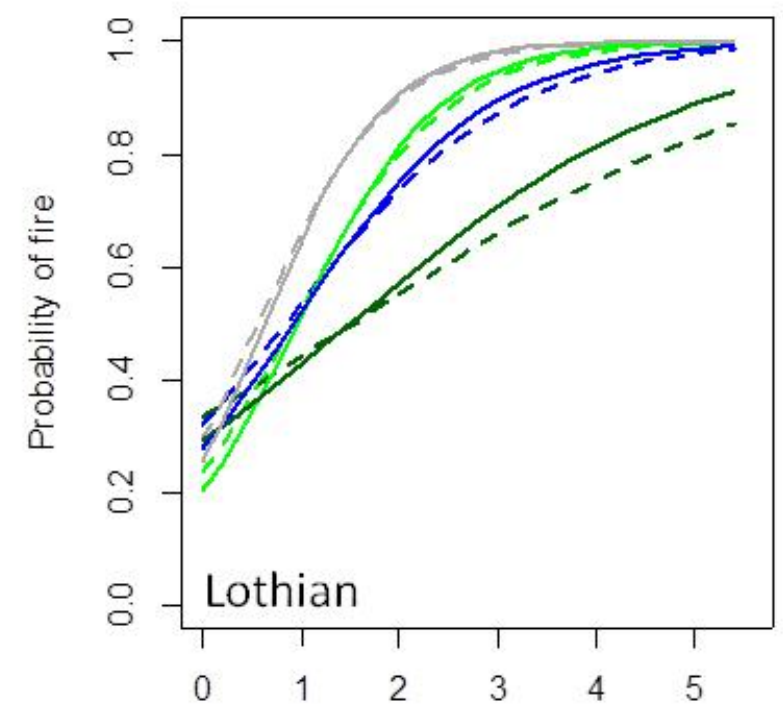

$|S|$

795 Figure 5: Modelled probability of wildfires in Scotland as a function of ISI and season for rural 796 (solid lines) and urban (<10 km from one of Scotland's 100 largest towns or cities; dotted lines)

797 locations across four regions of Scotland. Green = spring, dark green $=$ summer, blue $=$ autumn, 798 grey $=$ winter. 

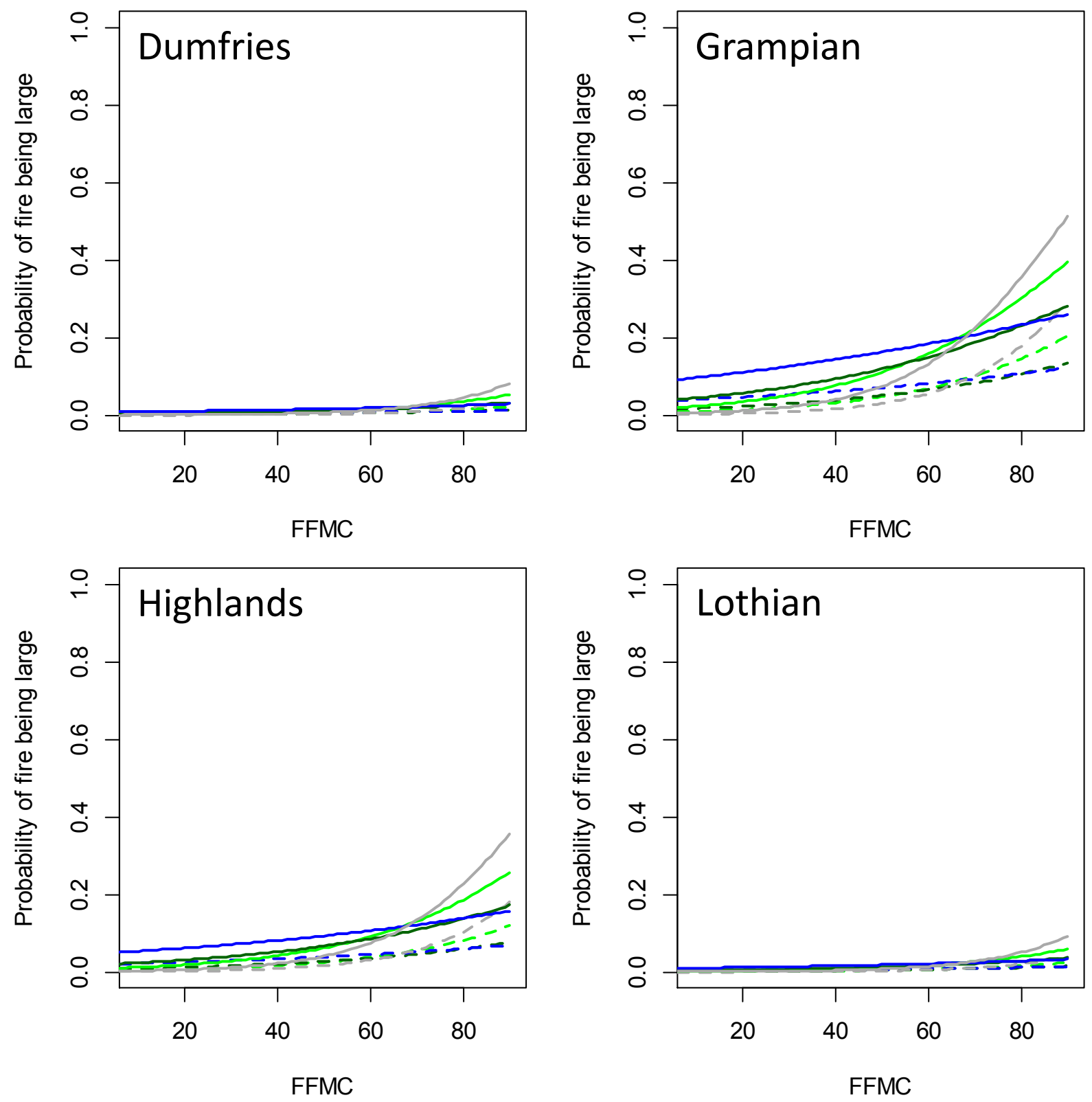

801 Figure 6: Modelled probability of observed wildfires in Scotland being "large" as a function of

802 FWI and season for rural (solid lines) and urban $(<10 \mathrm{~km}$ from one of Scotland's 100 largest

803 towns or cities; dotted lines) locations across four regions of Scotland. Green = spring, dark 804 green $=$ summer, blue $=$ autumn, grey $=$ winter 